\title{
Voltage Stability Analysis of Nigerian 330kV Power Grid using Static P-V Plots
}

\author{
E. N. Ezeruigbo ${ }^{a, *}$, A. O. Ekwue ${ }^{\mathrm{b}}$, L. U. Anih ${ }^{\mathrm{a}}$ \\ ${ }^{a}$ Department of Electrical Engineering, University of Nigeria, Nsukka, Enugu State, NIGERIA. \\ ${ }^{b}$ Jacobs Engineering Inc. London, UNITED KINGDOM.
}

\begin{abstract}
Nigeria power system has been experiencing total or partial system failures in recent times and voltage instability is a strong factor. The paper seeks to perform the voltage stability analysis, based on static P-V plots, on buses located around and within the South East zone of Nigeria. An injection group containing generators to serve as the source and a sink group as loads to be monitored are created. The generators are assumed to be within their min / max MW limits. The load is increased in the sink group as well as in the source group to maintain the same generation / load balance. Load power and bus voltages $(P-V)$ curves are plotted on the load busbars and the first busbar to reach the voltage collapse and $M W$ transfer limit are determined. From the results obtained, at a load of $100 \mathrm{MW}$, Makurdi bus recorded a voltage of $0.9301 \mathrm{pu}$ which is already below the regulatory standards of $\pm 5 \%$ of the nominal line voltage. It entered the region of instability at a load of $245 \mathrm{MW}$. This created a situation of system instability and a possible partial system collapse. Subsequently, at a load of $260 \mathrm{MW}$, the system clearly entered unstable region giving rise to partial system collapse of the network.
\end{abstract}

Keywords: P-V curves, voltage stability analysis, reactive power, power flow, partial system collapse

\section{INTRODUCTION}

Voltage stability is the ability of a power system to maintain acceptable voltages at all buses in the system under normal operating conditions and after being subjected to a disturbance [1]. It can also be defined as the ability of the system to maintain/restore equilibrium between load demands and supply [2].

It is the expectation of power system planners, designers, and operators that a power system operating condition should be stable, meeting various operational criteria, and it should also be secure in the event of any credible contingency. Present day power systems are being operated closer to their stability limits due to economic and environmental constraints. Maintaining a stable and secure operation of a power system is therefore a very important and challenging issue. Voltage stability of a power system is to a very large extent strongly related to the reactive power required to build the oscillating magnetic field of the power lines from generation to the load.

Power systems are required to maintain stability under any small or large disturbances imposed on them. Small signal disturbances arise from small perturbations like incremental changes in

\footnotetext{
* Corresponding author (Tel: +234 (0)803 666 1385)

Email addresses: emmaezeruigbo@gmail.com (E. N. Ezeruigbo), arthur.ekwue@gmail.com (A. O. Ekwue), linus.anih@unn.edu.ng (L. U. Anih)
}

load, load characteristics like constant power and constant impedance loads, and control actions inherent in the system.

Large system disturbances are due to faults, loss of generation, tripping of loaded transmission lines and other effects that create large power flow pattern. Essentially, inability of power system to meet the reactive power demand is largely responsible for voltage instability in a particular system [1]. A power system is in a state of instability when a disturbance like increase in load demand or change in system condition causes a progressive and uncontrollable decline in voltage.

The major contributory factors to voltage instability include:

i. Loss of load at some bus or an area: When low voltage is observed on some bus(es), the installed under-voltage relays will sense and act in a manner that the load on such bus(es) are put out of power supply for the voltage on such network or bus to improve. Otherwise the scenario may degenerate to the extent that the collapse of the power system may be imminent.

ii. Tripping of transmission line(s) due to faults: Large voltage drop in a power system is an indication that the transmission line is carrying large reactive power demand resulting in large amount of current flowing on the line. The situation is sensed by the over-current relays which act to isolate such lines. However, 
the distance protection of the transmission line is not so much affected by the changes in the load current or short circuit current magnitude unlike overcurrent relays [3]. When a highly distressed line trips, power will be routed through the interconnecting lines and they will experience or suffer the same effect as the already tripped line. This leads to cascade tripping in the network.

iii. Tripping of some generators due to field current violations: The generators are the major reactive power source in a transmission system. When reactive power demand is high, voltage levels drops and generators, through the Automatic Voltage Regulators (AVR) tries to maintain constant the terminal voltages. This attempt can lead to high excitation current of the generators. If the reactive power demand continues to increase in the system, leading to continuous drop in voltage, the generators will continue to maintain its terminal voltages constant through the action of the AVR.

If this is sustained, a time will be reached when there will be overcurrent in the excitation circuit. The overcurrent relays will operate to trip the generators due to high field current. The sequence of events highlighted above, which is a fallout of voltage instability, ultimately will lead to a total or partial blackout in an area in a phenomenon known as voltage collapse or very low voltages in a significant part of the system.

Transmission systems are becoming more stressed due to increased loads and inter - utility power transfers hence giving rise to threats of voltage instability and collapse [4]. In Nigeria, voltage instability problems are part of the reasons of power blackout or system collapse. Long distance transmission of electric power account for reasonable voltage drop as generation stations in the country are remotely located.

Fewer number of voltage control buses on account of few large generators make voltage control in Nigeria power system a big challenge. Sudden outage of these generator(s) or heavily loaded transmission lines are sources of voltage instability. A failure of a generator gives rise to loss of real and reactive power output in the grid.

Real power deficit can be compensated by the spinning reserve where it exists, the reactive power deficiency has no reserve capacity in the system. This further reduces the reactive power supply in the system thereby worsening the voltage drop and its attendant voltage instability [2].

\section{VOLTAGE STABILITY ANALYSIS}

Voltage stability analysis provides assessment of weak, unstable, or uncontrollable areas of the electrical network that may jeopardise future load growth due to unexpected voltage collapse. Conducting an effective voltage stability analysis is essential for system planning and long-term interoperability. For many decades, the increased demand in electricity and power transfers between utilities has elevated concerns about system voltage security. For that reason, voltage collapse has been considered responsible for several major disturbances [5].

Voltage collapse is often studied using bifurcation diagrams, where the bus voltages are plotted against load power levels (PV Curves). The most common methods to estimate the proximity of voltage collapse point are continuation load flow, direct methods and minimum singular value. A system is prone to collapse if there are heavy power flows into an area with insufficient reserves. A feature of this phenomenon is the speed which it can occur. Provision of adequate reactive reserves and maintenance of voltage collapse margins thus becomes a significant factor in economic operation of the power system [6].

Reduction of maximum power demand and improvement of load power factor can be achieved using shunt capacitors. However, under heavy load condition with low voltage, reactive power supply by these capacitors drops as reactive power supply by capacitors is proportional to $V^{2}$ given that

$$
Q=V^{2} Y^{c} \sin \theta
$$

where $Y^{c}$ is the susceptance of the shunt capacitor.

\section{TECHNIQUES OF VOLTAGE STABILITY ANALYSIS}

The voltage stability analysis can also be classified into static and dynamic analyses. Different methods have been reported in the literature for carrying out a steady - state voltage analysis. Power flow analysis is one of the techniques which are used to compute voltage magnitudes and phase angles at all buses. Other techniques include $V-P$ curves, $P-Q$ sensitivity analysis, $Q-V$ modal analysis, $Q-V$ curves, and Minimum Singular Value methods etc. In the static analysis, the snapshot of the system is taken from different time instances in time domain trajectory, hence useful information such as voltage stability and proximity to voltage collapse can be derived. The use of static technique is good enough for analysing voltage stability of a system. $P-V$ curve analysis is used to determine voltage stability of a radial system and a large meshed network. For this analysis $P$ i.e., power at a particular area is increased in steps and voltage $(V)$ is observed at some critical load buses and then curves for those particular buses will be plotted to determine the voltage stability of a system by static analysis approach [7]. On the other hand, in the dynamic analysis, a series of first-order differential equations are derived and can be solved using any integration methods such as Euler method, Rung-Kutta methods, numerical stability of explicit integration method or the implicit integration method. In dynamic analysis sequence of events that cause voltage instability can be analysed. Therefore, it is very vital to implement voltage instability analysis [8]. 


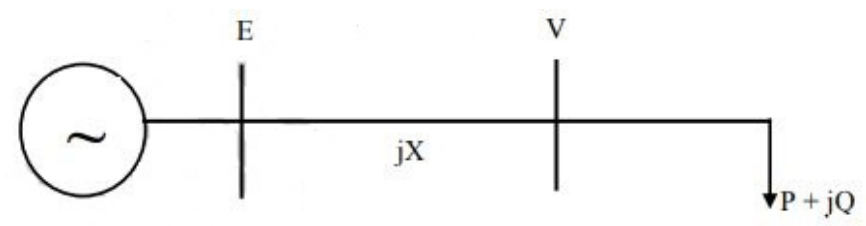

Figure 1: Simplified single machine network of a power system

The analysis of the voltage stability of a simple machine system of a power system is illustrated below [2]:

$$
V=E-j X I
$$

$V, E$, and $I$ are phasor quantities.

$$
S=P+j Q=V I^{*}
$$

$S$ is the complex power $=V\left(\frac{E^{*}-V^{*}}{-j X}\right)$, where $E$ is the voltage behind the reactance of the machine, $X$ is the reactance of the machine together with the transmission line and neglecting the resistance of the transmission line .

Expressing the rectangular coordinate formulation in a polar coordinate trigonometric form

$$
S=\frac{j}{X}\left(E V \cos \theta+j E V \sin \theta-V^{2}\right)
$$

Separating real and imaginary part

$$
\begin{gathered}
P=-\frac{E V \sin \theta}{X} \\
Q=-\frac{V^{2}}{X}+\frac{E V}{X} \cos \theta
\end{gathered}
$$

Squaring Eq. (5) and (6)

$$
\begin{gathered}
P^{2}=-\left(\frac{E V}{X}\right)^{2} \sin ^{2} \theta \\
{\left[Q+\frac{V^{2}}{X}\right]^{2}=\left(\frac{E V}{X}\right)^{2} \cos ^{2} \theta}
\end{gathered}
$$

Adding Eq. (7) and (8) and rearranging

$$
\begin{gathered}
P^{2}+Q^{2}+\frac{V^{4}}{X^{2}}=\left(\frac{E V}{X}\right)^{2}\left(\sin ^{2}+\cos ^{2}\right) \\
P^{2}+Q^{2}+\frac{V^{4}}{X^{2}}=\left(\frac{E V}{X}\right)^{2} \\
\left(P^{2}+Q^{2}\right) X^{2}+V^{4}=E^{2} V^{2} \\
\left(P^{2}+Q^{2}\right) X^{2}+\left(V^{2}\right)^{2}+2 Q X V^{2}=E^{2} V^{2}
\end{gathered}
$$

$$
\begin{aligned}
& \left(V^{2}\right)^{2}+2 Q X V^{2}-E^{2} V^{2}+\left(P^{2}+Q^{2}\right) X^{2}=0 \\
& \left(V^{2}\right)^{2}+V^{2}\left(2 Q X-E^{2}\right)+\left(P^{2}+Q^{2}\right) X^{2}=0
\end{aligned}
$$

A quadratic equation in $V^{2}$

$$
V=\left[\frac{E^{2}}{2}-Q X \pm \sqrt{\frac{E^{4}}{4}-P^{2} X-E^{2} Q X}\right]^{\frac{1}{2}}
$$

The solution of Eq. (15) is a double valued function [2]. A plot for $V$ as real power $P$ varies is shown in Fig. 2.

On the PV curves shown in Fig. 2, there are two solutions for voltage, one is the high voltage or stable solution, which is the actual voltage at the bus, and the other one is the low voltage or unstable solution. The knee point, along which the two solutions of $\mathrm{V}$ are equal, represents maximum power points. Starting from any operating point on the upper part of the surface, an increase in real power $(p)$ or reactive power $(q)$ or both brings the system closer to the maximum power point. An increase in $p$ or $q$ beyond the maximum power point makes the voltage unstable.

The system will experience a critical situation that will necessitate total or partial voltage collapse or system failure as it is usually the case in Nigeria. The voltage collapse is assumed to occur when either: (a) there is a change in sign (from negative to positive) of the sensitivity of voltage to reactive demand at any load busbar; or (b) the reactive reserves in the system are exhausted. The voltage collapse margin is then given by the increase in transfer calculated as a function of the voltage profile estimated at that point [6].

The system is better operated above the stable region where the operating voltage will be close to unity. Load cannot be sustained beyond the voltage collapse point or the maximum loadability point. Voltage at this point is the critical voltage value of the network. Beyond the voltage collapse point, if the load is increased a little, there will be a slight decrease in voltage with an increase in current to provide for the increased power.

For a constant power load, the curve will have a deeper curve [2]. $\mathrm{P}_{\max }$ is the maximum power obtainable from the system under the prevailing conditions and it occurs when the; load impedance is a complex conjugate of the line impedance or transfer impedance between the source and the receiving end [2]. A small change in power of the power system can be expressed as

$$
\triangle(P)_{\text {system }}=V \triangle I-I \triangle V
$$

For a small increase in load current, the extra power available will be approximately equal to increase in current multiplied by the original voltage less the original current multiplied by the decrease in voltage caused by the increased current flow on the line. 


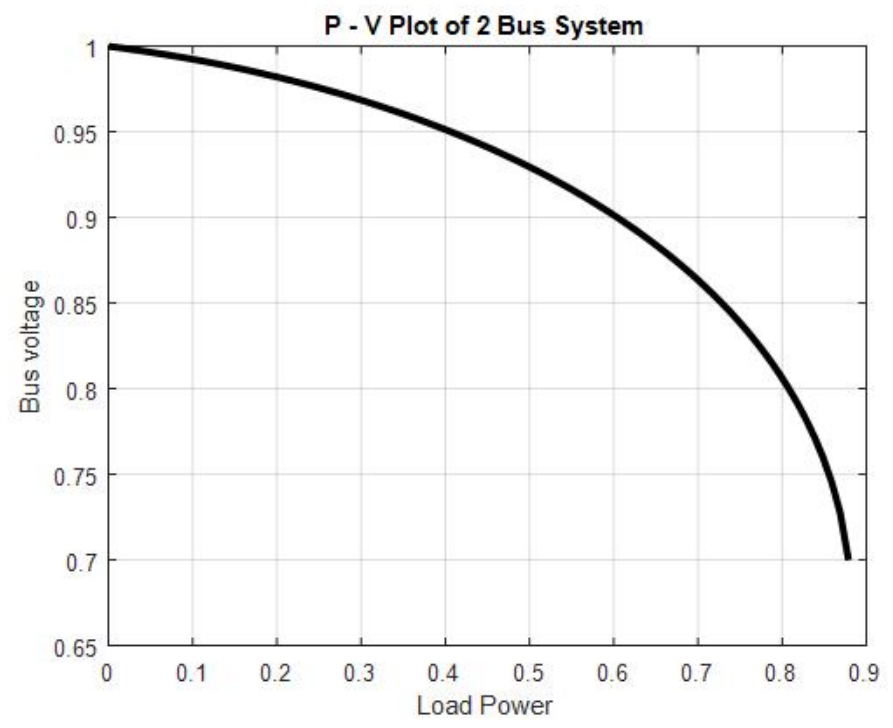

(a) P - V plot of 2 Bus system for the first solution.

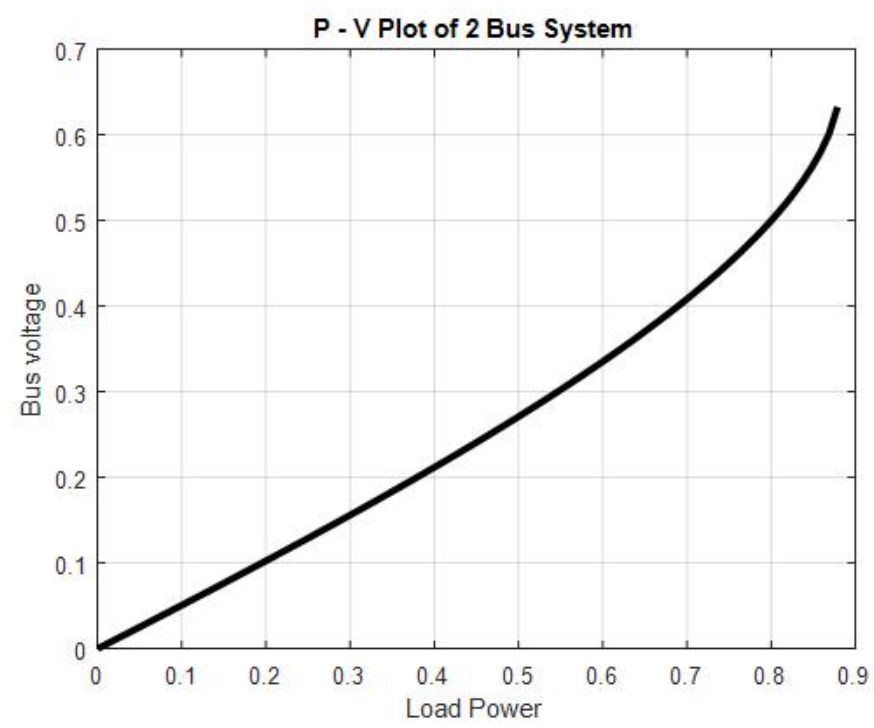

(b) $\mathrm{P}$ - V plot of 2 Bus system for the second solution.

Figure 2: PV Plot of a 2-bus system for the two solutions of the quadratic equation in Eq. 15.

Power demanded by the load will depend on its characteristics. In a constant power load $\Delta(\mathrm{P})=$ 0 .

$$
\triangle(P)=V \triangle I-I \triangle V \geq 0
$$

for the system to be stable. This condition is obtainable within the voltage collapse point of Fig. 3

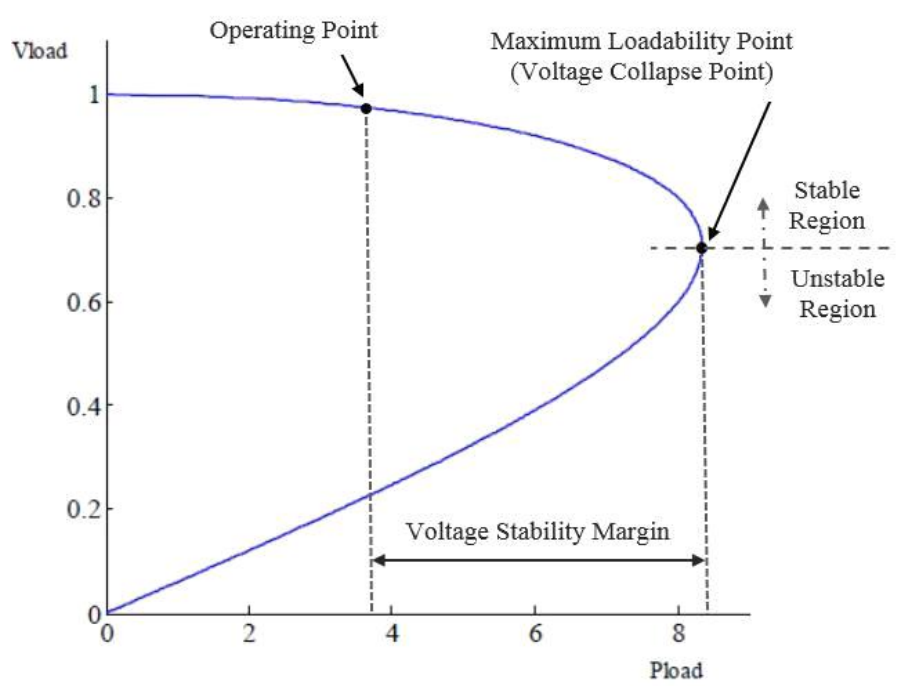

Figure 3: P - V Curve [9].

$$
V \triangle I-I \triangle V
$$

the greater than (sign) is applicable for a constant impedance load. The equality sign limit does not exist for a constant impedance load.

The Nigerian 36 -bus $330 \mathrm{kV}$ grid is shown in Fig. 4, indicating the voltage profile per unit at each of the buses obtained after a load flow analysis using PSS/E (Power System Software for Engineering version 34 ).
P-V curves are most widely used voltage stability analysis tool and are formed by increasing power at a particular area in steps and voltage (V) is observed at some critical load buses and then curves for those particular buses will be plotted. The P-V curve can provide real power and voltage margins using the knee of the curves as reference point. P-V curves at constant power factor are used to get maximum power transfer at critical voltage [4].

Voltage corresponding to "maximum loading point" is known as the critical voltage. If load is further increased, power flow equation does not have a solution. Hence, the P-V curve can be used to determine the system's critical voltage point and collapse margin. For a power system network, load buses (PQ buses) are identified to plot the P-V curves. Here, at load side real power $P$ and $Q$ are incremented at constant power factor. The steps in P-V curve analysis are:

1. Select a load bus(es), vary the load real power but with the power factor kept constant.

2. Compute the power flow solution for the present load condition and record the voltage of the load bus.

3. Increase the load real power by small amount and repeat step 2 until power flow does not have convergence.

4. P-V curve is plotted using the calculated load bus voltages for increased load values [4]

\section{PERFORMING STATIC P-V PLOTS}

The following buses were chosen as the injection source group:

1. Delta power station (P-V bus1) 


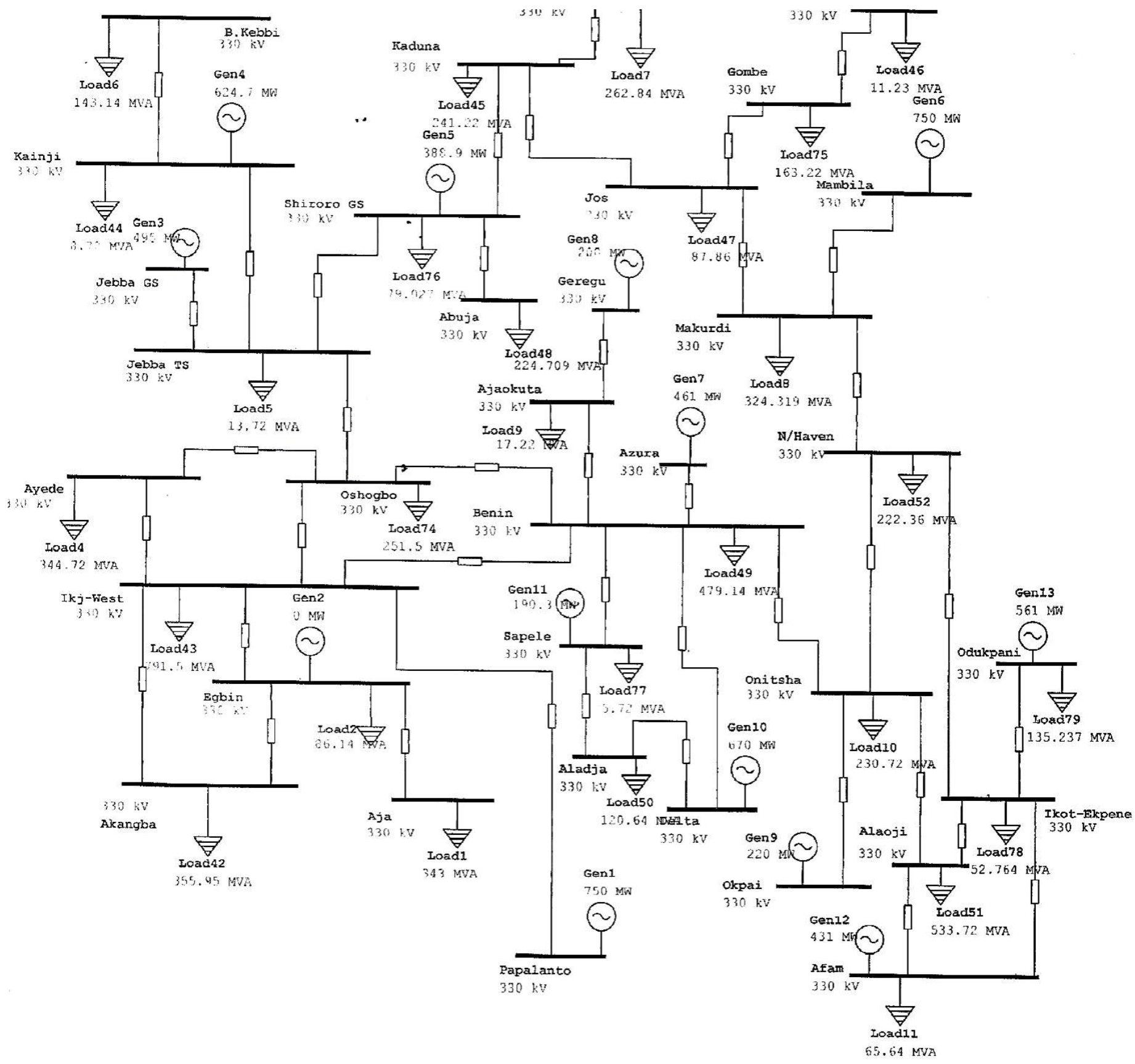

Figure 4: The Nigerian 36 -bus $330 \mathrm{kV}$ grid [10-13]. 


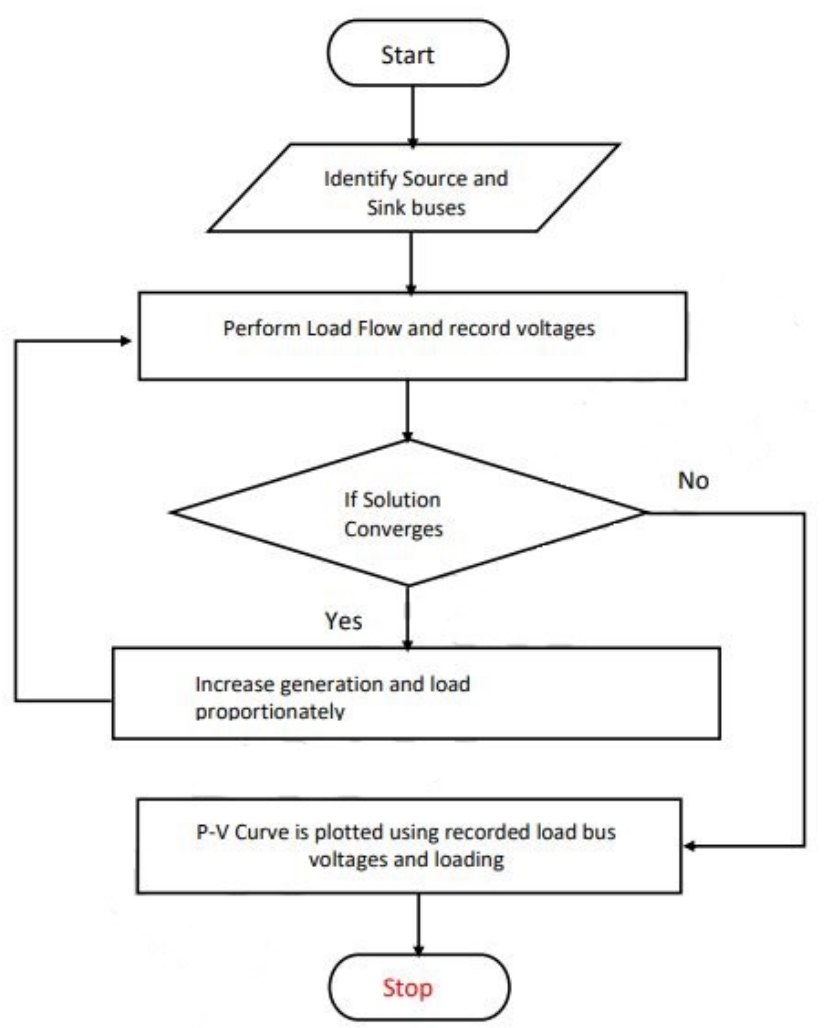

Figure 5: Operational flow chart

2. Sapele power station ( $\mathrm{P}-\mathrm{V}$ bus 2 )

3. Afam power station (P-V bus 3)

4. Okpai power station (P-V bus 4

5. Azura power station (Swing bus)

The sink group i.e. the attendant load buses are:

1. Benin (P-Q bus 1)

2. Onitsha (P-Q bus 2)

3. Aladja (P-Q bus 3)

4. New Haven (P-Q 4)

5. Alaoji (P-Q bus 5)

6. Afam TS (P-Q bus 6)

7. Makurdi (P-Q bus 7)

These buses were chosen with interest to the locations around South East geopolitical zone of Nigeria; it can be applied more widely too, if required. The operational flow chart is in Fig. 5.

\section{RESULTS AND DISCUSSION}

The network became unstable after 7-seven iterations: there was no more convergence of the Newton Raphson load flow technique at this instance. Voltage violation is apparent at Makurdi bus at an injected power and load of $100 \mathrm{MW}$,
$100 \mathrm{MV}_{\mathrm{Ar}}$ resulting in $0.9301 \mathrm{pu}$ volts in the sink (load) buses. It will be noted from Fig. 2 that the knee point of the P-V curve is within 0.7 and 0.65 pu. Above the knee point, the system operates in the stable region, below it is the region of instability. The result from Table 5 shows that the system has approached the knee point at the load of $240 \mathrm{MW}$. A partial or total collapse is evident at the load of $260 \mathrm{MW}$ with bus voltages at Afam, Makurdi, New Haven and Alaoji buses are below the knee point value. These are graphically illustrated in Fig. 6 and 7.

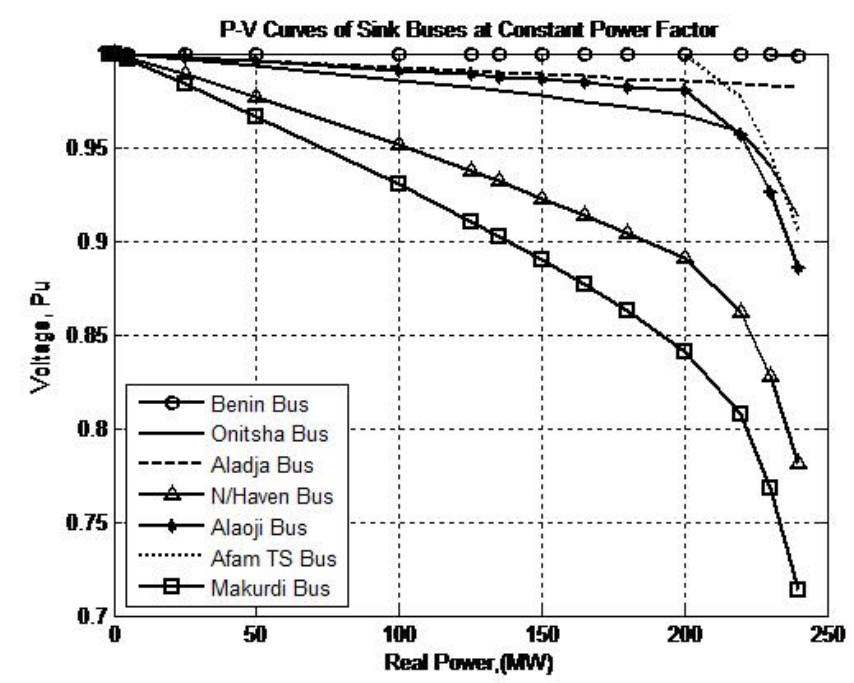

Figure 6: The P-V curves of the load buses (sink group) at critical point

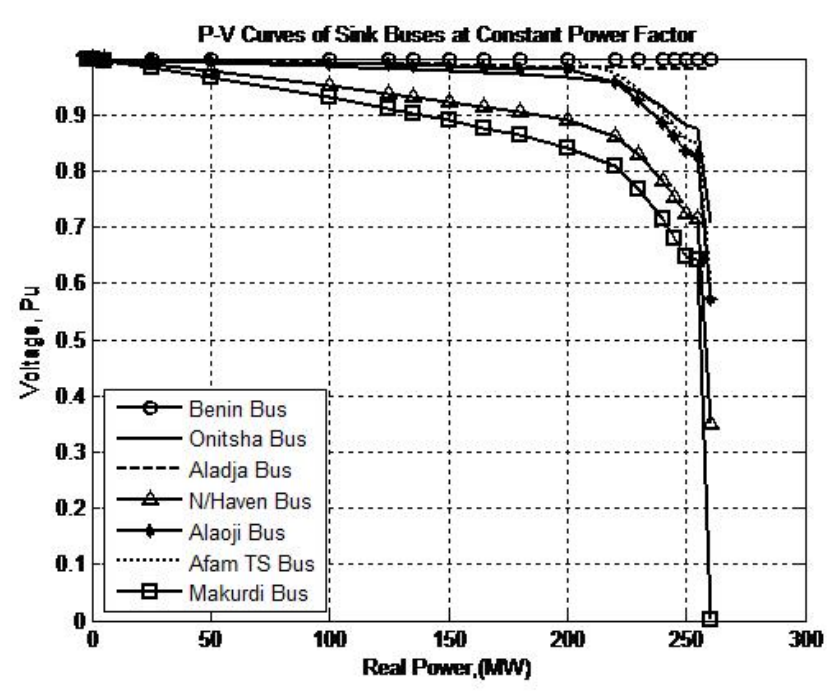

Figure 7: The P-V curves of the load buses (sink group) at unstable (partial collapse) condition

Associated with each bus are four quantities: active power $\mathrm{P}$, reactive power $\mathrm{Q}$, voltage magnitude $\mathrm{V}$ and voltage angle $\alpha$. At each bus, a specification of the known and unknown quantities is necessary. In this instance, direct load flow was carried out to monitor bus voltages in response to 
Table 1: The 36-bus Nigerian $330 \mathrm{kV}$ transmission grid is made up of the following buses [10-13].

\begin{tabular}{|c|c|c|c|c|c|c|c|}
\hline S/No. & Bus no. & Bus name & Base voltage $(\mathrm{kV})$ & $\begin{array}{l}\text { Gener } \\
\text { MW }\end{array}$ & $\begin{array}{l}\text { ration } \\
\text { MVAr }\end{array}$ & $\underset{\mathbf{M W}}{\mathbf{L o}}$ & $\begin{array}{l}\text { ad } \\
\text { MVAr }\end{array}$ \\
\hline 1 & 1 & Egbin (Slack Bus) & 330 & & & & \\
\hline 2 & 2 & Akamgba & 330 & & & 244.7 & 258.5 \\
\hline 3 & 3 & Aja & 330 & & & 274.4 & 205.8 \\
\hline 4 & 4 & Egbin ts & 330 & & & 68.9 & 51.7 \\
\hline 5 & 5 & Ikj-west & 330 & & & 633.2 & 474.9 \\
\hline 6 & 6 & Benin & 330 & & & 383.3 & 287.5 \\
\hline 7 & 7 & Sapele ps & 330 & 190.3 & & & \\
\hline 8 & 8 & Aladja & 330 & & & 96.5 & 72.4 \\
\hline 9 & 9 & Delta ps & 330 & 670 & & & \\
\hline 10 & 10 & Ajaokuta & 330 & & & 13.8 & 10.3 \\
\hline 11 & 11 & Geregu & 330 & 200 & & & \\
\hline 12 & 12 & Oshogbo & 330 & & & 201.2 & 150.9 \\
\hline 13 & 13 & Jebba ts & 330 & 11 & 8.2 & & \\
\hline 14 & 14 & Ayede & 330 & & & 275.8 & 206.8 \\
\hline 15 & 15 & Jebba gs & 330 & 495 & & & \\
\hline 16 & 16 & Kainji gs & 330 & 624.7 & & & \\
\hline 17 & 17 & B.kebbi & 330 & & & 114.5 & 85.9 \\
\hline 18 & 18 & Shiroro ts & 330 & & & 70.3 & 36.1 \\
\hline 19 & 19 & Shiroro gs & 330 & 388.9 & & & \\
\hline 20 & 20 & Kaduna & 330 & & & 193 & 144.7 \\
\hline 21 & 21 & Kano & 330 & & & 220.6 & 142.9 \\
\hline 22 & 22 & Abuja & 330 & & & 200 & 102.44 \\
\hline 23 & 23 & Afam & 330 & 431 & & & \\
\hline 24 & 24 & Alaoji & 330 & & & 427 & 320.2 \\
\hline 25 & 25 & Onitsha & 330 & & & 184.6 & 138.4 \\
\hline 26 & 26 & N/Haven & 330 & & & 177.9 & 133.4 \\
\hline 27 & 27 & Makurdi & 330 & & & 290.1 & 145 \\
\hline 28 & 28 & Jos & 330 & & & 70.3 & 52.7 \\
\hline 29 & 29 & Gombe & 330 & & & 130.6 & 97.9 \\
\hline 30 & 30 & Maiduguri & 330 & & & 10 & 5.11 \\
\hline 31 & 31 & Okpai & 330 & 220 & & & \\
\hline 32 & 32 & Papalanto & 330 & 750 & & & \\
\hline 33 & 33 & Mambila & 330 & 750 & & & \\
\hline 34 & 34 & Azura & 330 & 461 & & & \\
\hline 35 & 35 & Ikot-Ekpene & 330 & & & 45.8 & 26.2 \\
\hline 36 & 36 & Odukpani & 330 & 561 & & 112.8 & 74.6 \\
\hline
\end{tabular}


Table 2: The network data [10-13].

\begin{tabular}{|c|c|c|c|c|c|c|c|}
\hline \multirow{2}{*}{$\frac{\text { S/No. }}{1}$} & \multirow{2}{*}{ From bus no. } & Bus name & \multirow{2}{*}{ To bus no. } & \multirow{2}{*}{ Bus name } & Length $(\mathbf{k m})$ & \multicolumn{2}{|c|}{$\begin{array}{c}\text { Impedance } \\
\text { Resist. R Induct. X }\end{array}$} \\
\hline & & Egbin gs & & & & & \\
\hline 2 & 1 & Egbin ts & 2 & Akamgba & 86 & 0.0030 & 0.026100 \\
\hline 3 & 1 & Egbin ts & 3 & Aja & 27.5 & 0.000253 & 0.001948 \\
\hline 4 & 1 & Egbin ts & 5 & Ikj-west & 62 & 0.001122 & 0.008625 \\
\hline 5 & 2 & Akamgba & 5 & Ikj-west & 18 & 0.000304 & 0.002584 \\
\hline 6 & 5 & Ikj-west & 6 & Benin & 280 & 0.010100 & 0.017200 \\
\hline 7 & 5 & Ikj-west & 12 & Oshogbo & 252 & 0.008953 & 0.075987 \\
\hline 8 & 5 & Ikj-west & 14 & Ayede & 137 & 0.004900 & 0.041600 \\
\hline 9 & 5 & Ikj-west & 32 & Papalanto & 45 & 0.0016 & 0.011800 \\
\hline 10 & 6 & Benin & 7 & Sapele ps & 50 & 0.000904 & 0.006956 \\
\hline 11 & 6 & Benin & 9 & Delta ps & 41 & 0.001468 & 0.012462 \\
\hline 12 & 6 & Benin & 10 & Ajaokuta & 195 & 0.003492 & 0.029635 \\
\hline 13 & 6 & Benin & 10 & Ajaokuta & 195 & 0.003492 & 0.029625 \\
\hline 14 & 6 & Benin & 12 & Oshogbo & 251 & 0.008989 & 0.076291 \\
\hline 15 & 6 & Benin & 25 & Onitsha & 137 & 0.002453 & 0.02082 \\
\hline 16 & 6 & Benin & 34 & Azura & 1 & 0.000018 & 0,000139 \\
\hline 17 & 7 & Sapele ps & 8 & Aladja & 63 & 0.002256 & 0.019149 \\
\hline 18 & 8 & Aladja & 9 & Delta ps & 32 & 0.001146 & 0.009726 \\
\hline 19 & 10 & Ajaokuta & 11 & Geregu & 1 & 0.000018 & 0.000139 \\
\hline 20 & 12 & Oshogbo & 13 & Jebb & 157 & 0.002811 & 0.02386 \\
\hline 21 & 12 & Oshogbo & 14 & Ayede & 115 & 0.004118 & 0.034954 \\
\hline 22 & 13 & Jebba ts & 15 & Jebba gs & 8 & 0.000145 & 0.001113 \\
\hline 23 & 13 & Jebba ts & 16 & Kainji gs & 81 & 0.00145 & 0.01231 \\
\hline 24 & 13 & Jebba ts & 18 & Shir & 244 & 0.004369 & 0.037082 \\
\hline 25 & 16 & Kainji & 17 & B.Kebbi & 310 & 0.005551 & 0.047112 \\
\hline 26 & 18 & Shiroro ts & 20 & Kaduna & 96 & 0.001719 & 0.01459 \\
\hline 27 & 18 & Shiroro gs & 22 & $\begin{array}{l}\text { Abuja } \\
\text { (Katempe) }\end{array}$ & 218 & 0.003944 & 0.030328 \\
\hline 28 & 20 & Kaduna & 21 & Kano & 230 & 0.004118 & 0.034954 \\
\hline 29 & 20 & Kaduna & 28 & Jos & 196 & 0.00351 & 0.029787 \\
\hline 30 & 23 & Afam & 24 & Alaoji & 25 & 0.000432 & 0.003478 \\
\hline 31 & 23 & Afam & & $\begin{array}{l}\text { Ikot- } \\
\text { eknene }\end{array}$ & 87.7 & 0.0030 & 0.02610 \\
\hline 32 & 24 & Alaoji & 35 & $\begin{array}{l}\text { Ikot- } \\
\text { ekpene }\end{array}$ & 51.1 & 0.000915 & 0.006956 \\
\hline 33 & 24 & Alaoji & 25 & Onitsha & 138 & 0.0049 & 0.041945 \\
\hline 34 & 35 & $\begin{array}{l}\text { Ikot- } \\
\text { ekpene }\end{array}$ & 26 & N/Haven & 234 & 0.004500 & 0.031600 \\
\hline 35 & 35 & Ikot- & 36 & Odukpani & 112.5 & 0.004128 & 0.001213 \\
\hline 36 & 25 & Onitsha & 26 & N/Haven & 96 & 0.003438 & 0.029179 \\
\hline 37 & 25 & Onitsha & 31 & Okpai & 60 & 0.001085 & 0.008347 \\
\hline 38 & 26 & N/Haven & 27 & Makurdi & 195 & 0.002100 & 0.017400 \\
\hline 39 & 27 & Makurdi & 28 & Jos & 275 & 0.002900 & 0.024600 \\
\hline 40 & 28 & Jos & 29 & Gombe & 264 & 0.004727 & 0.040121 \\
\hline 41 & 29 & Gombe & 30 & Maiduguri & 284 & 0.010000 & 0.079600 \\
\hline 42 & 27 & Makurdi & 33 & Mambila & 353 & 0.0079 & 0.059100 \\
\hline
\end{tabular}


Table 3: The network data [10-13].

\begin{tabular}{|c|c|c|c|c|c|c|c|c|}
\hline S/No. & Bus no. & Bus name & Base voltage $(\mathrm{kV})$ & Voltage (pu) & Angle $\left(^{\circ}\right)$ & Generation & Lo & ad \\
\hline 1 & 1 & Egbin (Slack Bus) & 330 & 1.0000 & 0.00 & & & \\
\hline 2 & 2 & Akamgba & 330 & 0.934 & 64.49 & & 244.7 & 258.5 \\
\hline 3 & 3 & Aja & 330 & 0.9953 & -0.28 & & 274.4 & 205.8 \\
\hline 4 & 4 & Egbin ts & 330 & 0.9984 & 0.06 & & 68.9 & 51.7 \\
\hline 5 & 5 & Ikj-west & 330 & 0.9365 & 5.33 & & 633.2 & 474.9 \\
\hline 6 & 6 & Benin & 330 & 0.9992 & 18.80 & & 383.3 & 287.5 \\
\hline 7 & 7 & Sapele ps & 330 & 1.0000 & 19.90 & 190.3 & & \\
\hline 8 & 8 & Aladja & 330 & 0.9984 & 21.09 & & 96.5 & 72.4 \\
\hline 9 & 9 & Delta ps & 330 & 1.0000 & 22.19 & 670 & & \\
\hline 10 & 10 & Ajaokuta & 330 & 0.9999 & 19.97 & & 13.8 & 10.3 \\
\hline 11 & 11 & Geregu & 330 & 1.0000 & 19.99 & 200 & & \\
\hline 12 & 12 & Oshogbo & 330 & 0.9163 & 16.42 & & 201.2 & 150.9 \\
\hline 13 & 13 & Jebba ts & 330 & 0.9918 & 26.84 & & 11 & 8.2 \\
\hline 14 & 14 & Ayede & 330 & 0.8672 & 7.88 & & 275.8 & 206.8 \\
\hline 15 & 15 & Jebba gs & 330 & 1.0000 & 27.10 & 495 & & \\
\hline 16 & 16 & Kainji gs & 330 & 1.0000 & 30.39 & 624.7 & & \\
\hline 17 & 17 & B.kebbi & 330 & 0.9935 & 30.66 & & 114.5 & 85.9 \\
\hline 18 & 18 & Shiroro ts & 330 & 0.8497 & 21.39 & & 70.3 & 36.1 \\
\hline 19 & 19 & Shiroro gs & 330 & 1.0000 & 28.17 & 388.9 & & \\
\hline 20 & 20 & Kaduna & 330 & 0.7667 & 17.56 & & 193 & 144.7 \\
\hline 21 & 21 & Kano & 330 & 0.6719 & 9.65 & & 220.6 & 142.9 \\
\hline 22 & 22 & Abuja & 330 & 0.7979 & 16.60 & & 200 & 102.44 \\
\hline 23 & 23 & Afam & 330 & 1.0000 & 27.29 & 431 & & \\
\hline 24 & 24 & Alaoji & 330 & 0.9835 & 26.62 & & 427 & 320.2 \\
\hline 25 & 25 & Onitsha & 330 & 0.9723 & 22.45 & & 184.6 & 138.4 \\
\hline 26 & 26 & N/Haven & 330 & 0.8845 & 24.68 & & 177.9 & 133.4 \\
\hline 27 & 27 & Makurdi & 330 & 0.8125 & 26.57 & & 290.1 & 145 \\
\hline 28 & 28 & Jos & 330 & 0.7530 & 19.95 & & 70.3 & 52.7 \\
\hline 29 & 29 & Gombe & 330 & 0.6785 & 14.17 & & 130.6 & 97.9 \\
\hline 30 & 30 & Maiduguri & 330 & 0.6710 & 13.25 & & 10 & 5.11 \\
\hline 31 & 31 & Okpai & 330 & 1.0000 & 23.33 & 220 & & \\
\hline 32 & 32 & Papalanto & 330 & 1.0000 & 10.29 & 750 & & \\
\hline 33 & 33 & Mambila & 330 & 1.0000 & 56.98 & 750 & & \\
\hline 34 & 34 & Azura & 330 & 1.0000 & 18.83 & 461 & & \\
\hline 35 & 35 & Ikot-Ekpene & 330 & 0.9797 & 27.53 & & 45.8 & 26.2 \\
\hline 36 & 36 & Odukpani & 330 & 1.0000 & 27.50 & 561 & 112.8 & 74.6 \\
\hline
\end{tabular}

Table 4: Bus bars with low voltages below regulatory standard of $\pm 5 \%$ on nominal value.

\begin{tabular}{|c|c|c|c|c|c|c|c|c|}
\hline \multirow{2}{*}{ S/No. } & \multirow{2}{*}{ Bus no. } & \multirow{2}{*}{ Bus name } & \multirow{2}{*}{ Base voltage $(\mathrm{kV})$} & \multirow{2}{*}{ Voltage (pu) } & \multirow{2}{*}{ Angle $\left(^{\circ}\right)$} & \multirow{2}{*}{$\begin{array}{l}\text { Generation } \\
\mathbf{M W} \mathbf{M V}_{a r}\end{array}$} & \multicolumn{2}{|c|}{ Load } \\
\hline & & & & & & & MW & $\mathbf{M} \mathbf{V}_{a r}$ \\
\hline 1 & 2 & Akamgba & 330 & 0.9346 & 4.49 & & 244.7 & 258.5 \\
\hline 2 & 5 & Ikj-West & 330 & 0.9365 & 5.33 & & 633.2 & 474.9 \\
\hline 3 & 12 & Oshogbo & 330 & 0.9163 & 16.42 & & 201.2 & 150.9 \\
\hline 4 & 14 & Ayede & 330 & 0.8672 & 7.88 & & 275.8 & 206.8 \\
\hline 5 & 18 & Shiroro ts & 330 & 0.8497 & 21.39 & & 70.3 & 36.1 \\
\hline 6 & 20 & Kaduna & 330 & 0.7667 & 17.56 & & 193 & 144.7 \\
\hline 7 & 21 & Kano & 330 & 0.6719 & 9.65 & & 220.6 & 142.9 \\
\hline 8 & 22 & Abuja & 330 & 0.7979 & 16.60 & & 200 & 102.44 \\
\hline 9 & 26 & N/Haven & 330 & 0.8845 & 24.68 & & 177.9 & 133.4 \\
\hline 10 & 27 & Makurdi & 330 & 0.8125 & 26.57 & & 290.1 & 145 \\
\hline 11 & 28 & Jos & 330 & 0.7530 & 19.95 & & 70.3 & 52.7 \\
\hline 12 & 29 & Gombe & 330 & 0.6785 & 14.17 & & 130.6 & 97.9 \\
\hline 13 & 30 & Maiduguri & 330 & 0.6710 & 13.25 & & 10 & 5.11 \\
\hline
\end{tabular}


Table 5: Voltage monitoring on load buses due to incremental loading.

\begin{tabular}{|c|c|c|c|c|c|c|c|c|c|c|}
\hline \multirow{2}{*}{\multicolumn{2}{|c|}{$\begin{array}{c}\text { Source } \\
\mathbf{P}(\mathbf{M W}) \mathbf{Q}\left(\mathbf{M V} \mathbf{V}_{A r}\right)\end{array}$}} & \multirow{2}{*}{\multicolumn{2}{|c|}{$\begin{array}{c}\text { Sink } \\
\mathbf{P}(\mathbf{M W}) \mathbf{Q}\left(\mathbf{M V}_{A r}\right)\end{array}$}} & \multirow{3}{*}{$\frac{\text { Benin }}{1.0000}$} & \multirow{3}{*}{$\frac{\text { Afam }}{1.0000}$} & \multicolumn{3}{|c|}{ Load Bus Voltage (pu) } & \multirow{3}{*}{ Alaoji } & \multirow{3}{*}{ Aladja } \\
\hline & & & & & & Makurdi & Onitsha & N/Haven & & \\
\hline 0 & 0 & 0 & 0 & & & 1.0000 & 1.0000 & 1.0000 & & \\
\hline 5 & 5 & 5 & 5 & 1.0000 & 1.0000 & 0.9968 & 0.9994 & 0.9978 & 0.9996 & 0.9996 \\
\hline 25 & 25 & 25 & 25 & 0.9999 & 1.0000 & 0.9837 & 0.9967 & 0.9886 & 0.9979 & 0.9982 \\
\hline 50 & 50 & 50 & 50 & 0.9998 & 1.0000 & 0.9666 & & & 0.9957 & 0.9964 \\
\hline 100 & 100 & 100 & 100 & 0.9997 & 1.0000 & 0.9301 & & & 0.9911 & 0.9927 \\
\hline 125 & 125 & 125 & 125 & 0.9 ؟ & 1.0000 & 0.9 & & & 0.9887 & 0.9909 \\
\hline 135 & 135 & 135 & 135 & $0.9 \varsigma$ & 1.0 & 0.9 & & & 777 & 0.9901 \\
\hline 150 & 150 & 150 & 150 & 0.9 & 1.0 & & 2 & 0.9 & 361 & 0.9890 \\
\hline 165 & 165 & 165 & 165 & 0.99 & 1.0000 & 0.8 & 0.9 & $0 . \varsigma$ & 45 & 0.9879 \\
\hline 180 & 180 & 180 & 180 & & 1.00 & & & & 21 & 68 \\
\hline 200 & 200 & 200 & 200 & & & & & & & \\
\hline 220 & 220 & 220 & 220 & 0.9 & 0.9 & & & & 36 & 0.9 \\
\hline 230 & 230 & 230 & 230 & & & & & & & \\
\hline 240 & 240 & 240 & 240 & 0.9 & 0.9 & 0.7 & & & 52 & 0.9822 \\
\hline 245 & 245 & 245 & 245 & & & & & & & \\
\hline 250 & 250 & 250 & 250 & $0.9 ؟$ & 0.8565 & 0.6 & & & 52 & 0.9815 \\
\hline 255 & 255 & 255 & 255 & & & & & & & \\
\hline 260 & 260 & 260 & 260 & 0.9975 & 0.5967 & 0.0001 & 0.7076 & 0.3496 & 0.5127 & 0.9807 \\
\hline
\end{tabular}

imposed contingencies in the network.

Power systems across the world today are subjected to heavy demands owing to widespread expansions in the networks. This has forced the power systems to operate closer to its stability limit due to environmental and economic constraints. Overloading of an already stressed system may lead to voltage collapse when the bus voltage drops to such a level from which it cannot recover, and if ignored, may result in complete system shutdown [8]. This is the scenario that played out as shown in Fig. 7.

Voltage collapse point is the point on the P-V curve, at which the Jacobian matrix of power flow equations is singular. It is well known that voltage instability is characterised by a change in sign of the sensitivity of voltage to demand, i.e., the sensitivity of the nodal voltage $V i$; to the nodal injection of active power $P i$ at a constant power factor [6].

\section{CONCLUSION}

Voltage instability, as a factor in system collapse, is evident in the power system studied above. The vulnerability to low voltages of some buses in the grid is also exposed. The inability of the power system to meet the demand of reactive power is largely responsible for low voltage situation in the power grid. Buses where low voltage is inherent are candidate buses for reactive power compensation and necessary power system reinforcement and intervention.

Good number of measures can be adopted to improve voltage stability and hence ensure system stability devoid of collapses.

1. Deployment of embedded generation closer to the load centres will reduce the effects of longdistance transmission and its attendant voltage drop.

2. Reasonable increase in generating capacity adequate to meet demand and provide for contingencies arising from transient failures, increase in demand and loss of generating capacity.

3. Flexible AC Transmission System (FACTS) devices can improve the lines active power capability in any contingency event and application of reactive power compensation devices like STATCOM, series and shunt capacitors. Also, to carry out under voltage load shedding scheme, operate the system in such a manner that the reactive power capability of the generators are conserved and other devices like STATCOM, shunt and series capacitors can be incorporated so that the generator majorly provides the real power at unity power factor.

4. Design of the power system to have inherent stability margin based on MW and MVAr to instability.

5. Selection of sizes, ratings and location shall be guided by a detailed study covering the system conditions of operation.

6. Effective control of network voltage and generator reactive power output. Voltage regulation is better managed at the generator buses through maintenance of constant generator terminal voltage through the action of the automatic voltage regulators (AVRs).

7. Effective coordination of the protection/control scheme of the power system and prompt response to system dynamics is very vital.

\section{References}

[1] M. Kothari, "Lecture on power system dynamics," Educational Technology Services Centre IIT, Delhi, India, February 2019.

[2] A. Sinha, "Lecture on power system analysis," Indian Institute of Technology, kharagpur, India. 
[3] U. Uzubi, A. Ekwue, and E. Ejiogu, "Adaptive distance relaying: Solution to challenges of conventional protection schemes in the presence of remote in feeds," International Transactions on Electrical Energy Systems, vol. e12330, 2020, https://doi.org/10.1002/20507038.12330.

[4] M. Parihar, M. Bhaskar, D. Bohra, and D. Sarvate, "Pvcurve analysis of 3 bus power system using MATLAB," International Journal of Emerging Trends \& Technology in Computer Science (IJETTCS) ISSN, pp. 22786856.

[5] N. Fnaiech, A. Jendoubi, and F. Bacha, "Voltage stability analysis in power system using continuation method and psat software," in 6th International Renewable Energy Congress, (IREC), Tunisia, March 2015.

[6] A. Ekwue, H. Wan, D. Cheng, and Y. Song, "Voltage stability analysis on the ngc system," Electric Power Systems Research Journal, vol. 43, no. 3, pp. 173-180, 1998.

[7] M. Gupta and S. Matharu, "PV and Q V Curve Analysis of IEEE 9 Bus System," Int. Journal of Engineering Research and Application, vol. 8, no. 4, pp. 01-05, 2018.

[8] I. Anichebe and A. Ekwue, "Improvement of Bus Voltage Profiles of Nigeria Power Network in the Presence of Static Synchronous Compensator (STATCOM) and Double Fed Induction Generator," Nigerian Journal of Technology, vol. 39, no. 1, pp. 228-237, 2020.

[9] H. M. Mostafa, "A thesis on voltage stability and power flow studies of distribution system including distributed generation," Master's thesis, Faculty of Engineering, Cairo University, Owseem City, Giza, Egypt, June 2016.

[10] F. Agbontaen and S. Ike, "Loadability Analysis of the Existing 330kv Transmission Network of the Nigerian Electricity Grid," Nigerian Research Journal of Engineering and Environmental Sciences, vol. 2, no. 2, pp. 416-423, 2017.

[11] R. A. Jokojeje, I. A. Adejumobi, A. O. Mustapha, and O. I. Adebisi, "Application of Static Synchronous Compensator (Statcom) in Improving Power System Performance: A Case Study of the Nigeria $330 \mathrm{kV}$ Electricity Grid," Nigerian Journal of Technology, vol. 34, no. 3, pp. $564-572,2015$

[12] U. C. Ogbuefi and T. C. Madueme, "A Power Flow Analysis of the Nigerian $330 \mathrm{KV}$ Electric Power System," Journal of Electrical and Electronics Engineering (IOSR-JEEE), vol. 10, no. 1, pp. 46-57, 2015.

[13] I. K. Okakwu, E. A. Ogujor, and P. A. Oriaifo, "Load Flow Assessment of the Nigeria 330-kV Power System," American Journal of Electrical and Electronic Engineering, vol. 5, no. 4, pp. 159-165, 2017. 